\title{
Impairment Strained Analytical Modeling Evaluation and Cross-talk Analysis of Symmetric and Coexistent Channels for Extended Class-1 NG-PON2 Access Network
}

Rajendraprasad Pagare ( $\nabla$ rapagare@rediffmail.com )

Smt Kashibai Navale College of Engineering Vadgaon https://orcid.org/0000-0003-0295-0344

Abhilasha Mishra

MIT: Maharashtra Institute of Technology Aurangabad

Santosh Kumar

Liaoning University

\section{Research Article}

Keywords: XGS-PON, WDM, NG-PON2 PON, TWDM

Posted Date: March 8th, 2022

DOI: https://doi.org/10.21203/rs.3.rs-1323627/v1

License: (c) (1) This work is licensed under a Creative Commons Attribution 4.0 International License.

Read Full License 


\title{
Impairment strained analytical modeling evaluation and cross-talk analysis of symmetric and coexistent channels for extended class-1 NG-PON2 access network
}

\author{
Rajendraprasad A. Pagare, ${ }^{* 1}$ Abhilasha Mishra, ${ }^{2}$ Santosh Kumar $^{3}$
}

\begin{abstract}
The analytical modeling for channel linear and non-linear impairments (LNI) and simulative analysis of extended power budget class-1 i.e. E1-class of next generation passive optic network-2 (NG-PON2) delivering symmetric 2.5 point-to-multi point (PtM) representing time and wavelength division multiplexing (TWDM) XGS-PON along with $10 \mathrm{Gbps}$ point-to-point (PtP) wavelength division multiplexing (WDM) symmetric and coexistent channels in worst-case scenario is presented in the paper. Channel modelling of LNI is carried out under the incremental and aggregate strain of estimated chromatic dispersion CD, selfphase modulation (SPM), cross-phase modulation (XPM) of single mode fiber (SMF) channel deployed in optical distributing network (ODN) between 20 - $50 \mathrm{~km}$ link lengths. Downlink (D/L) and uplink (U/L) ODN is optimized to $\mathrm{PT}_{\mathrm{ODN}}=7.1 \mathrm{dBm}$ and $4.09 \mathrm{dBm}$ respectively and corresponding channel imparities including Kerr parameter $\gamma$, corresponding SPM, XPM, CD, four-wave mixing (FWM) analysis and corresponding component power and efficiency, interchange crosstalk $(C c)$ attracting power penalties $(P c)$ are estimated and incorporated in the simulation for the real response of lossy SMF channel. Further, splitter power budget (SP) and slitter configuration for respective PtM and PtP D/L channels are estimated under the aggregate impact of CD, SPM, XPM and FWM. Analytical modeling of LNI and simulative analysis has confirmed the configuration delivered rise in receiver sensitivity (Rxs) of -39.75/-33.45 dBm and -29/-35.34 dBm for D/L and U/L channels respectively. The estimated power of FWM element is between $1.34 \times 10^{-52}$ to $2.15 \times 10^{-53}$ and $3.87 \times 10^{-52}$ to $2.41 \times 10^{-51}$ contributing crosstalk between channels $(C c)$ of $-31.97 /-30.12 \mathrm{~dB}$ for down/up spectrum under the impact of SPM and XPM respectively accommodating splitter configuration of 768 at 40 $\mathrm{km}$.
\end{abstract}

\section{Keywords}

XGS-PON · WDM · NG-PON2 PON · TWDM

Corrosponding author: Rajendraprasad A. Pagare ${ }^{\mathbf{1}}$

Email id: rapagare@ rediffmail.com

Extended author information available on the last page of the article 


\section{Introduction}

Gigabit access line rate, high bandwidth, ensured quality-of-services (QoS), reliability and secured means of communication has already established optical access networks (OAN) as prime contender for deployment of NG-PON based applications. Users demand for faster, reliable and secure access network is not only intact post Covid-19 situation but also on the rise in future. In fact, gigabit OAN have become an integral part of every human being and the society contributing in the socio-economic development of the users and the society. Incorporating new age and disruptive technologies including Artificial Intelligence (AI), Neural Networks (NN) and Data Science Techniques (DST) have significantly improved the user experience, design, reconfigure, upgreadation, monitoring and maintenance of the NG-PON OAN. WDM along with TWDM will be leading technology option for design and deployment of backhaul as well as fronthaul access networks. The demand of higher bandwidth and line rate by almost all the domains of the business including future schools, universities, agriculture, healthcare, banking, finance, gaming and entertainments, smart city applications will be supported by NG-PON2 OAN. Cisco has projected in all around 50 Billion users including fixed line internet, mobile and machine-to-machine (MtM) by 2023 will required bandwidth in the range of 44-110 Mbps per user to access new age applications (Way et al. 2016; Yuanqiu et al. 2016; Cisco 2019; Koundal et al. 2019).

TWDM has outplayed optical code division and orthogonal frequency division multiple access techniques to configuration NG-PON2 networks as described by G. $989.2(02 / 2019 / 2015 / 2013)$ specifications and standards. Flexibility in network expansions, coexistence feasibility with legacy access network like GPON and XG-PON enhancing PtM and PtP nodes leading to cost-effective expansion of access networks are the key features of TWDM technology. TWDM NG-PON2 access networks can deliver symmetric 1.25 to 10 Gbps line rate can be expanded seamlessly to support $80 \mathrm{Gbps}$ aggregate line rate by incorporating an array of eight 10 Gbps symmetric line rate channels (Veen et al. 2015; Jeff et al. 2012; Goyal et al., 2017; TUT-T G. 989.2, 2019; Kumar et al. 2014).

Analytical modeling and estimation of nonlinearities introduced by SMF in ODN is critical process to experience real response of SMF channel on optical spectrum travelling through the SMF. Precise estimation of SMF channel imparities including CD, SPM, XPM will help to estimate magnitude of FWM components, 
channel crosstalk $(C c)$, power penalties $(P c)$, network reach, link power budget (PB, SP splitter ratio which can be supported by $\mathrm{D} / \mathrm{L}$ channels.

The structure of the paper is organized in six sections. Section one includes the abstract, need and the key features of the proposed network concept. The architecture of the prescribed E1-class of TWDM NG-PON 2 network and wavelength plan is described in second section. The subsequent section includes the design and optimization process of OLT, ONU, ODN launch power and estimation of $\mathrm{D} / \mathrm{L}$ and $\mathrm{U} / \mathrm{L}$ transmitter power for XGS-PON PtM and WDM PtP symmetric channels. Post optimization of ODN to E1-class, the estimation and optimization of SMF for nonlinearities including Kerr parameter $\gamma$, CD, SPM, XPM, FWM and channel cross talk is described in section four. The simulative analysis of the proposed network configuration is presented in section five along with link power budget and splitter configuration analysis. Finally, conclusion based on design, simulation and analysis of the proposed network and possible future task is discussed in sixth section. The optimization process has achieved incremental receiver sensitivity of $-39.75 /-33.45 \mathrm{dBm}$ and $-29 /-35.34 \mathrm{dBm}, C c$ of $-31.97 /-29.93 \mathrm{~dB}$, with $0 \mathrm{~dB}$ of crosstalk penalty $(P c)$ of or D/L and U/L channels receiver respectively accommodating aggregate splitter configuration in the range of 512-2560 between 40 $\mathrm{km}$ and $20 \mathrm{~km}$ with aggregate impact of FWM, SPM, XPM and CD impairments.

\section{Block schematic of E1-Class TWDM NG-PON2 optical access network}

The block scheeatic of the foreseen E1-class of NG-PON2 multichannel network supporting coexistence functionality along with symmetric 2.5 and $10 \mathrm{Gbps}$ channels is presented in Fig. 1. The schematic includes three section namely optical line terminal (OLT) tranceivers (Trx)housing meachnism for D/L transmitter channels and U/L recivers. Optical network unit (ONU) consists of mecahnism for detectection of D/L channels and transission of U/L channels. The third section accomodates ODN section deployed using bidirectional SMF carrying multichannellspectrumin either direction. The channal are identified as sederreciver channel pairs (S/R-CP) at OLT Trx, seder-reciver channel group (S/R-CG) at at the output port of eight channel WDM also known as coexistence element (CEx). The applications and services encoded in the form of bits are connected to to network throughsender network interface (SNI) and connected to users at ONUs through user network interface (UNI) (Kumar et al. 2014; Neophytos et al. 2012; ITU-T G. 652 2019). Downlink channels divided in to two groups repreenting four each PtM 2.5 Gbps XGS-PON and PtP 10 Gbps 
WDM in either direction. D/L channels are transmitted on L-band wavelenghth plan betwwn 187.1 to 187.8 THz while U/L channels are broadcased on $195.1 \mathrm{THz}$ to $195.8 \mathrm{THz}$ C-band frequencies withhannel spacing of $\Delta F=100 \mathrm{GHz}$ supporting symmetric $80 \mathrm{Gbps}$ aggrigate line rate. ODN section is implemented using $\mathrm{G}$. 652 lossy bidirectional SMF covering distance between 20 to $50 \mathrm{~km}$ (Way et al. 2016; Yuanqiu et al. 2016; Veen et al. 2015; Jeff et al. 2012; Kumar et al. 2014; IX Blue Photo. 2019).

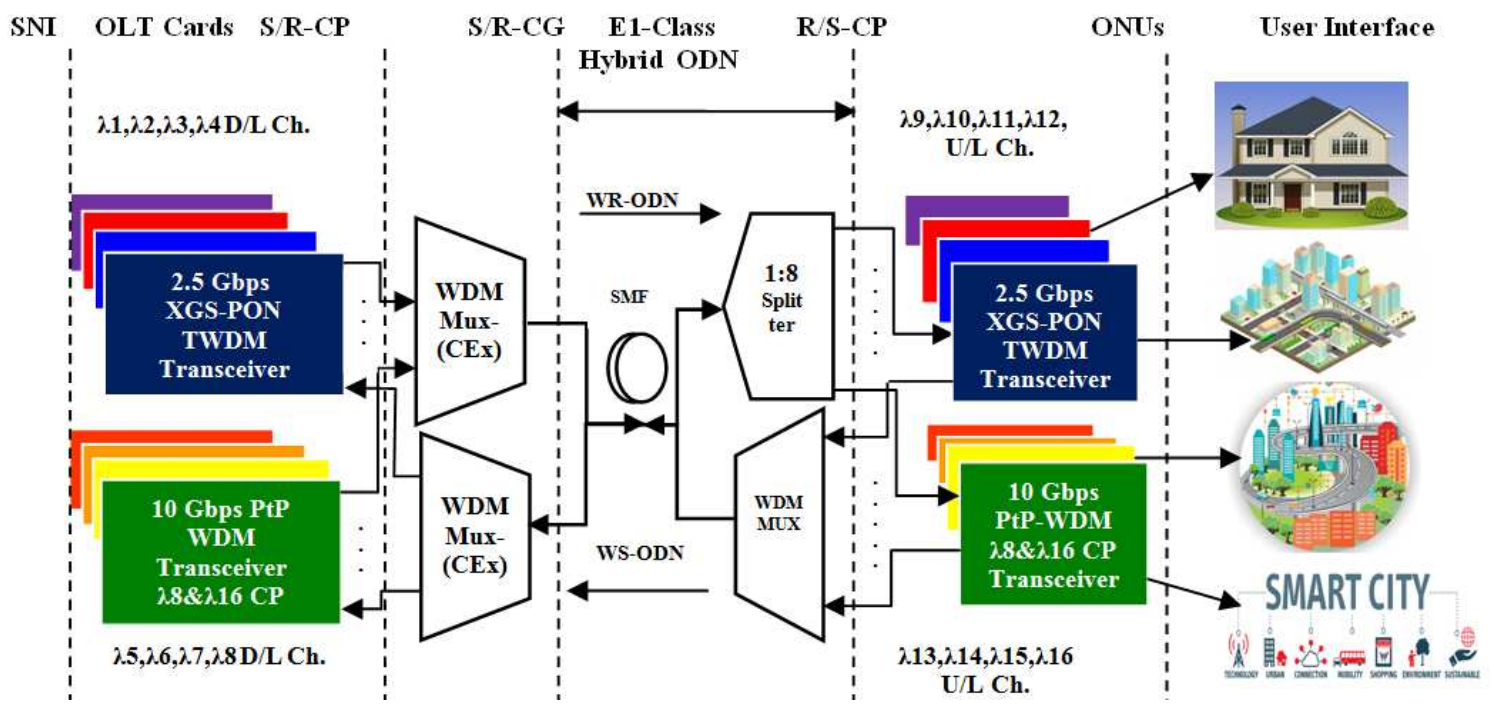

Fig. 1 Extended class-1 TWDM NG-PON2 schematic

\section{Design and optimization of N2-class NG-PON2 network subsystems}

\subsection{Simulation mechanism of OLT transceiver}

OptiSystem-18 simulation software is used for the design and simulation of proposed E1-class access network. OptiSystem provides the reach variety of active and passive components' along the lossy and lossless unidirectional and bidirectional fiber channels. The post simulation analysis can be carried out efficiently and effectively with latest and advanced set of test and measurement equipment's and visualizers. The simulation setup for single OLT Trx is depicted in Fig. 2. It consists of mechanism for D/L transmitter channels and receiver for U/L channels. Continuous wave $(\mathrm{CW})$ laser is used for D/L optical transmitters. Widely used Mech-Zender Modulator (MZM) which is also known as intensity modulator (IM) is incorporated to achieve modulation of optical carrier signal. The OLT Trx mechanism depicted in Fig. 2 is repeated for eight $\mathrm{D} / \mathrm{L}$ and $\mathrm{U} / \mathrm{L}$ channels. The modulated multichannel optical spectrum is applied to eight channel WDM CEx. The aggregate intensity of eight optical $\mathrm{D} / \mathrm{L}$ channels represented as $\mathrm{PT}_{\mathrm{ODN}}=$ 
$\sum_{n=1}^{8} A_{k}(t)=7.1 \mathrm{dBm}$ is launed through SMF in ODN in downstream direction at S/R-CG interface. The $\mathrm{U} / \mathrm{L}$ spectrum is made to propagated through Bessel filter before being detected by positive-intrinsic-negative (PIN) photodetector. The demodulated signal is propagated through LPF before being applied to BER analyzer for analysis purpose. $\mathrm{PT}_{\mathrm{ODN}}$ is optimized to $7.1 \mathrm{dBm}$ to keep the impact of channel nonlinearities at minimum level to enhance the performance of the network in terms of crosstalk and FWM components $[11,17,21,36]$. The intensity of the $\mathrm{U} / \mathrm{L}$ spectrum is identifies as $\mathrm{PT}_{\mathrm{ODN}}=\sum_{\mathrm{n}=1}^{8} \mathrm{~B}_{\mathrm{k}}(\mathrm{t})$ is optimized to $4 \mathrm{dBm}$ at S/R-CG interface $[1,2,9,10]$.

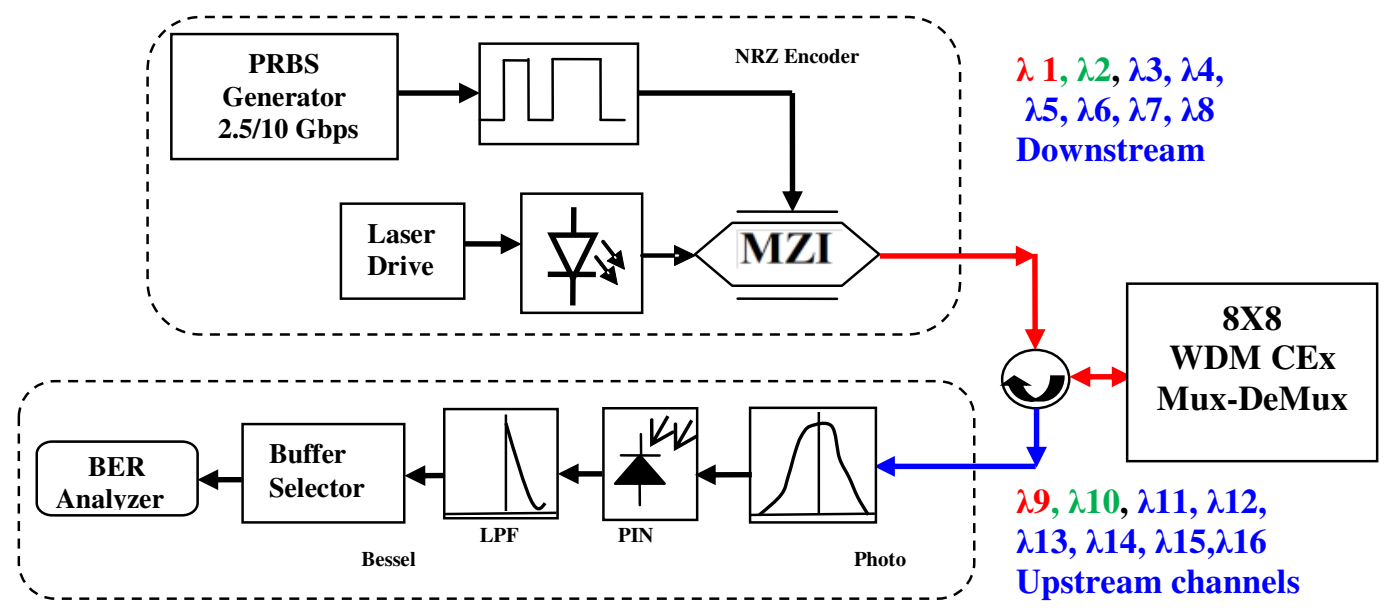

Fig. 2 Extended class-1 TWDM NG-PON2 OLT Transceiver

The $\mathrm{D} / \mathrm{L}$ and $\mathrm{U} / \mathrm{L}$ spectrum $\mathrm{PT}_{\mathrm{ODN}}$ is optimized by referring the insertion losses (IL) introduced by MZM intensity modulator, WDM CEx devices and the circulators of $5.04 \mathrm{~dB}, 2.6 \mathrm{~dB}$, and $1 \mathrm{~dB}$ respectively (IX Blue Photonics 2019; Ciena Corp. 2011; Cornig Opt. 2016) incorporated to establish D/L channels. Individual transmitter channel power $\mathrm{P}_{\mathrm{TX} \lambda}$ is selected randomly ensuring the aggregate transmitter power of input channels is almost near to total ILs estimated using generate and test model (Pagare et al. 2021) described by Eq.1 as,

$\mathrm{P}_{\mathrm{TODN}}=\mathrm{P}_{\mathrm{TX} \lambda}-\sum_{\mathrm{M}=1}^{\mathrm{N}-1} \mathrm{P}_{\mathrm{IL} \_\mathrm{MZI}}-\sum_{\mathrm{C}=1}^{\mathrm{N}-1} \mathrm{P}_{\mathrm{IL} \_\mathrm{Cir}}-\mathrm{P}_{\mathrm{IL} \_\mathrm{MUX}}+\sum_{\lambda=1}^{\mathrm{N}-1} \mathrm{P}_{\mathrm{Tin} \_\mathrm{MUX}}$

Before optimizing $\mathrm{P}_{\mathrm{TX} \lambda}$, randomely selected transmitter power from eigth $\mathrm{D} / \mathrm{L}$ channela has generated aggregate power of $48.40 \mathrm{~dB}$ at the input ports of CEx device i.e. selected $\sum_{\lambda=1}^{\mathrm{N}-1} \mathrm{P}_{\mathrm{TinMUX}}=48.40$. Replacing the IL of respective component and aggregate input power at CEx device in Eq. 1, the newly estimated 
channel transmitter power of 2.5 and $10 \mathrm{Gbps} \mathrm{D} / \mathrm{L}$ to optimize $\mathrm{P}_{\mathrm{TODN}}=7 \mathrm{dBm}$ of E1-class is estimated using Eq. 2 as,

$\mathrm{PT}_{\mathrm{ODN}}=\mathrm{PT}_{\mathrm{X \lambda}}-(5.04 \times 8)-(1 \mathrm{x} 8)-2.6+48.40$

$\mathrm{PT}_{\mathrm{TODN}}=\mathrm{PT}_{\mathrm{X} \lambda}-2.55$

$\mathrm{PT}_{\mathrm{X} \lambda}=\mathrm{PT}_{\mathrm{ODN}}+2.55$

Referring minimum and maximum $\mathrm{P}_{\text {TODN }}$ form ITU-T. 989.2 (02/2019) standards to optimize E1-class ODN operating 2.5 and 10 Gbps channels, transmitter power $\mathrm{PT} \times \lambda$ of individual downstream (D/S) channel is estimated using Eq. 2 as,

$\mathrm{PT}_{\mathrm{X} \lambda_{\_} \text {min_D } / \mathrm{L} \_2.5 \mathrm{Gbps}}=4+2.55=6.55 \mathrm{dBm}$

$\mathrm{PT}_{\mathrm{X} \lambda_{\_} \text {max_D } / \mathrm{L} 2.5 \mathrm{Gbps}}=8+2.55=10.55 \mathrm{dBm}$

$\mathrm{PT}_{\mathrm{X} \lambda \_ \text {min_D/L } 10 \mathrm{Gbps}}=7+2.55=9.55 \mathrm{dBm}$

$\mathrm{PT}_{\mathrm{X} \lambda \_ \text {max_D/L } 10 \mathrm{Gbps}}=11+2.55=13.55 \mathrm{dBm}$

The sensitivity of 2.5 and $10 \mathrm{Gbps}$ U/L channels is estimated by using Eq. 3 as (ITU-T G.989.2 2019),

Receiver sensitivity $($ Rxs $)=$ Received Sensitivity $(\mathrm{dBm})-\left[\mathrm{IL}_{\text {TотAL }}+\right.$ Power Penalty $]>30.5 \mathrm{dBm} 3$

The total IL of individual channel link is estimated by adding insertion losses of individual passive components in the link. Total IL estimated for XGS-PON PtM 2.5 and WDM PtP 10 Gbps D/L channels are as follows.

$\mathrm{IL}_{\mathrm{TOTAL}}=\mathrm{IL}($ Dynamic Switch + Mux + DeMUX + Circulator $)$

$\mathrm{IL}_{\text {TOTAL_2.5 PtM_XGS-PON }}=3.24+2.6+2.6+2=10.44 \mathrm{~dB}$

$\mathrm{IL}_{\text {TOTAL_10 PtP_WDM }}=\mathrm{IL}(\mathrm{MZI}+$ Circulator + Mux + DeMux + Circulator $)$

$\mathrm{IL}_{\mathrm{TOTAL}}=5.04+1+2.6+2.6+1=12.24$

Incorporating total estimated insertion losses in Eq. 3, the Rxs for XGS-PON PtM 2.5 and WDM PtP 10 Gbps U/S channels is estimated by using Eq. 3 as,

$\mathrm{R}_{\mathrm{XGS} 2.5 \text { PtM_XGS-PON_U/L }}=-16.56-[10.44+2]=-29 \mathrm{dBm}>-30.5 \mathrm{Bm}$

$\mathrm{R}_{\mathrm{XGS} 10 \text { PtP_WDM_U/L }}=-21.1-[12.24+2]=-35.34 \mathrm{dBm}>-30.5 \mathrm{dBm}$

\subsection{Simulation mechanism of ONU transceiver}

Simulation mechanism houses assembly of passive optical components to demodulate and receive D/L channels and transmit U/L channels. D/L channels are detected by tunable PIN photo receivers along with 
Bessel filter and TFF based LPF as presented in Fig. 3. U/L channels are established using cost-effective NRZ encoded direct modulated laser transmitter (DML) along with along with 2-stage of dynamic switches to connect subscribers from upstream direction in TWDM mode [25]. PtP WDM U/L channels are established using NRZ encoded MZM/IM operating at $10 \mathrm{Gbps}$ line rate. To estimate optimized channel transmitter power, randomly selected power of eight U/L channels has resulted in aggregate power of $43.52 \mathrm{dBm}$ at the input of WDM CEx device. Knowing the IL of passive components, the U/L channel transmitter power is estimated using Eq. 4 and Eq. 5 as (Pagare et al. 2021),

$\mathrm{PT}_{\mathrm{ODN}}=\mathrm{P}_{\mathrm{TX} \lambda}-\sum_{\mathrm{M}=1}^{\mathrm{N}-1} \mathrm{P}_{\mathrm{ILMZM}}-\sum_{\mathrm{C}=1}^{\mathrm{N}-1} \mathrm{P}_{\mathrm{ILCir}}-\mathrm{P}_{\text {ILswitch }}-\mathrm{P}_{\text {ILMUX }}-\mathrm{P}_{\text {ILBid-Splitter }}+\sum_{\lambda=1}^{\mathrm{N}-1} \mathrm{P}_{\text {TinMUX }}$

$\mathrm{PT}_{\mathrm{ODN}}=\mathrm{P}_{\mathrm{TX} \lambda}-(30.71+8+2.40+2.6+1.25)+43.52$

$\mathrm{PT}_{\mathrm{ODN}}=\mathrm{P}_{\mathrm{TX} \lambda}-1.44$

Replacing minimum and maximum ODN launch power defined for XGS-PON PtM 2.5 and WDM PtP 10 Gbps U/S channels by G.989.2 standards in Eq. 5, U/S channel transmitter power $\mathrm{PT}_{\mathrm{X} \lambda}$ for 2.5 and $10 \mathrm{Gbps}$ $\mathrm{U} / \mathrm{S}$ channels are estimated as,

$\mathrm{P}_{\mathrm{TX} \lambda \_\min \_\mathrm{U} / \mathrm{S}}=4+1.44=5.44$ for E1-Class XGS-PON PtM 2.5 and WDM PtP 10 Gbps U/S channels $\mathrm{P}_{\mathrm{TX} \lambda \_\max _{-} \mathrm{U} / \mathrm{S}}=9+1.44=10.44$ for E1-Class XGS-PON PtM 2.5 and WDM PtP 10 Gbps U/S channels

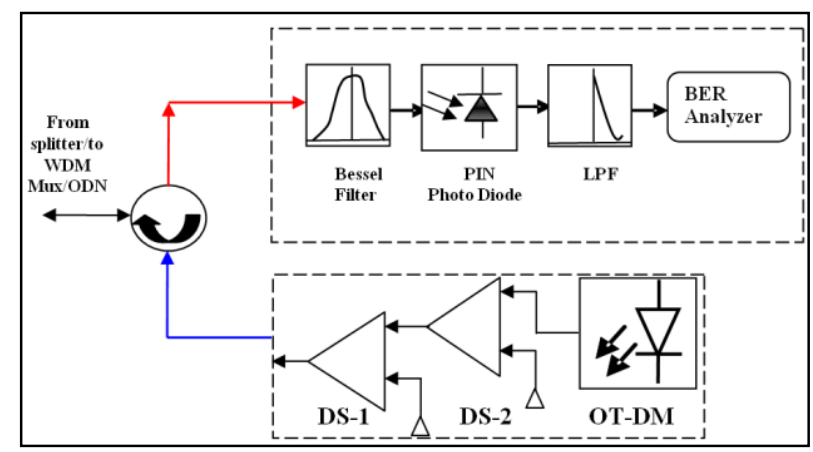

Fig. 3 Simulation mechanisms for TWDM ONU transceiver

The receiver sensitivity (Rxs) of XGS-PON PtM 2.5 and WDM PtP 10 Gbps D/S channels is estimated by using Eq. 6 as (ITU-T G.989.2 2019),

Rxs $=$ Received Sensitivity $(\mathrm{dBm})-\left[\mathrm{IL}_{\mathrm{TOTAL}}+\right.$ Power Penalty $]>-30 \&-28 \mathrm{dBm}$

where; $\mathrm{IL}_{\mathrm{TOTAL}}=\mathrm{IL}(\mathrm{MZI}+\mathrm{Mux}+$ Circulator $)$ in dB. Total IL for XGS-PON PtM 2.5 and WDM PtP 10 Gbps D/S channels is estimated as, 
$\mathrm{IL}_{\text {TOTAL }}=5.04+2.6+1=8.64 \mathrm{~dB}$ for XGS-PON PtM 2.5 Gbps D/S channels

$\mathrm{IL}_{\text {TOTAL }}=5.04+2.6+2=9.64 \mathrm{~dB}$ for WDM PtP $10 \mathrm{Gbps} \mathrm{D} / \mathrm{S}$ channels

Since G.989.2 standard has defined $2 \mathrm{~dB}$ of power penalty for worst-case analysis of NG-PON2 [9], using

Eq. 6, sensitivity of XGS-PON PtM 2.5 and WDM PtP $10 \mathrm{Gbps}$ D/S channel is calculated as,

$\mathrm{R}_{\mathrm{XGS} 2.5 \text { XGS-PON_D/S }}=-29.11-[8.64+2]=-39.75 \mathrm{dBm}>-30 \mathrm{dBm}$

$\mathrm{R}_{\mathrm{XGS} 10 \text { PtP_WDM_D/S }}=-21.81-[9.64+2]=-33.45 \mathrm{dBm}>-28 \mathrm{dBm}$

\subsection{Simulative mechanism for E1-class ODN}

Since the ODN for the foreseen E1-power budget class TWDM NG-PON2 network is optimized to PT ODN $_{\text {. }}$ $=7.1 \mathrm{dBm}$ and $4.01 \mathrm{dBm}$ respectively for $\mathrm{D} / \mathrm{L}$ and $\mathrm{U} / \mathrm{L}$ spectrum, the transmitter power of the respective symmetric and coexistent channels estimated in section 3.1 and 3.2 in the along with aggregate effect of $\mathrm{CD}$, SPM and XPM is summarized in Table 1. [9].

Table 1 Range of transmitter input power $\left(\mathrm{PT}_{\mathrm{X} \lambda}\right)$ to ensure $\mathrm{PT}_{\mathrm{ODN}}=7.1 \mathrm{dBm}$ for $\mathrm{D} / \mathrm{S}$ and $4.01 \mathrm{dBm}$ for $\mathrm{U} / \mathrm{S}$ spectrum respectively for E1- class TWDM NG-PON2 access network under the cumulative impact of estimated CD, SPM and XPM channel impairments

\begin{tabular}{cccccc}
\hline $\begin{array}{c}\text { TWDM } \\
\text { NG-PON2 } \\
\text { Class }\end{array}$ & $\begin{array}{c}\text { Range of } \\
\text { PT } x \lambda\end{array}$ & $\begin{array}{c}\text { 2.5 Gbps } \\
\text { XGS-PON } \\
\text { PtM D/S Ch. }\end{array}$ & $\begin{array}{c}\text { 10 Gbps } \\
\text { PtP WDM } \\
\text { D/S Ch. }\end{array}$ & $\begin{array}{c}\text { 2.5 Gbps } \\
\text { XGS-PON } \\
\text { PtM U/S Ch. }\end{array}$ & $\begin{array}{c}\text { 10 Gbps } \\
\text { PtP WDM } \\
\text { U/S Ch. }\end{array}$ \\
\hline $\begin{array}{c}\text { E1-Class } \\
\text { NG-PON2 }\end{array}$ & Minimum & $6.55 \mathrm{dBm}$ & $9.55 \mathrm{dBm}$ & $5.44 \mathrm{dBm}$ & $5.44 \mathrm{dBm}$ \\
& Maximum & $10.55 \mathrm{dBm}$ & $13.55 \mathrm{dBm}$ & $10.44 \mathrm{dBm}$ & $10.44 \mathrm{dBm}$ \\
\hline
\end{tabular}

The $\mathrm{D} / \mathrm{L}$ and $\mathrm{U} / \mathrm{L}$ multichannel optical spectrum is propagated through wavelength routed (WR) ODN and wavelength select (WS) ODN. The measured ODN channel path loss is $18.99 \mathrm{~dB}$, much less than the specification defined by G.989.2 standard. Low ODN losses will enhances the link power budget and splitter budget to support higher splitter configuration in $2.5 \mathrm{Gbps}$ PtM D/L channels [2,9].

\section{Fiber channel impairment estimation and analysis for N2-class NG-PON2 network}

The optimized multichannel optical spectrum with magnitude of $7.1 \mathrm{dBm}$ and $4.01 \mathrm{dBm}$ is propagated through bidirectional SMF in either direction. The propagation of the optical spectrum is analyzed using Schrodinger nonlinear equation (NLSE) represented by Eq. 7 as (Kumar et al. 2014; Neophytos et al. 2012; ITU-T G.652 2019), 
$\frac{\partial A}{\partial z}+\frac{i \beta_{2}}{2} \frac{\partial^{2} A}{\partial t^{2}}+\frac{\alpha}{2} A-i \gamma\left|A^{2}\right| A=0$

where $A$ is intensity of slowly varying optical envelope in $(\mathrm{V} / \mathrm{m}), \beta_{2}$ is group velocity dispersion (GVD) measured in $\left(\mathrm{ps}^{2} \mathrm{~km}^{-1}\right)$ also identified as CD, parameter, $\mathrm{z}$ - Spatial position in fiber axis in (m), $\gamma$ - non-linear Kerr parameter in $\left(\mathrm{W}^{-1} \mathrm{~km}^{-1}\right)$ contributing SPM and XPM impairments. Non-linear Kerr parameter $\gamma$ is estimated using Eq. 8 as (Kumar et al. 2014; Neophytos et al. 2012; Ali et al. 2018),

$\gamma=\frac{2 \pi n_{2}}{\lambda_{0} A_{e f f}}$

It is observed that the optical field envelope intensity $A$ is affected by Kerr parameter $\gamma$ contributing SPM and XPM impairments, GVD or CD parameter $\beta_{2}$ and non-linear refractive index $n_{2}$. Thus, by optimizing linear and non-linear channel impairments, the network performance parameters like bit error rate (BER), Q-factor, Rxs, power and splitter budget can be enhanced (Kumar et al. 2014; Neophytos et al. 2012; Habib et al. 2020).

\subsection{Chromatic dispersion (CD) coefficient estimation}

The impact of $\mathrm{CD}$ on the optical spectrum propogating through fiber channel appears interms of spreading of the the optical pulse or envelope effecting BEperformance. The CD parameter proportional to fiber channel length $L$ and and the channel wavelength $D_{\text {Link }}(\lambda)$ is estimated using Eq. 9 as (ITU-T G.989.2 2019; ITU-T G.652 2019),

$D_{\text {Link }}(\lambda)=L_{\text {Link }}\left[\mathrm{D}_{1550}+\mathrm{S}_{1550}(\lambda-1550)\right](\mathrm{ps} / \mathrm{nm} * \mathrm{~km})$

At $1550 \mathrm{~nm}$, the dispersion coefficient and dispersion slope is $1550 \mathrm{~nm}$ and $12 \mathrm{ps} / \mathrm{nm} * \mathrm{~km} 0.056 \mathrm{ps} / \mathrm{nm}^{2} * \mathrm{~km}$ respectivelly for G.652 fiber channel [12]. The CD coefficient of $19.744 \mathrm{ps} / \mathrm{nm} * \mathrm{~km}$ is estimated using Eq. 9 and incorporated for simulative analysis of foreseen network between 20 -50 km SMF channel length (Kumar et al. 2014).

\subsection{Non-liner kerr parameter- $\gamma$ and Effective area- $A_{\text {eff }}$ estimation}

Since the fiber silica is sensitive to the intensity of the optical spectrum launched through fiber channel. Any variations in the non-linear refractive index $n_{2}$ due to variations in magnitude of intensity of the optical spectrum results in non-linear phase change $\emptyset_{N L}$ of the optical signal propagating through fiber channel proportional to kerr parameter $\gamma$. Further, $\gamma$ is responsible for SPM and XPM channel impairments based on amount of non-linear phase change introduced due to variations in the magnitude of the intensity of optical 
spectrum. The net effect of SPM and XPM appear in the form of overlapping of adjacent channels reducing BER performance. The non-linear phase change due to SPM and XPM is estimated using Eq. 10 and Eq. 11 as (Kumar et al. 2014; Neophytos et al. 2012; Habib et al. 2020; Singh et al. 2018),

$\emptyset_{N L_{X P M}}=\gamma L_{e f f} P T_{O D N}^{p}+2 \sum_{\mathrm{p}=1, \mathrm{p} \neq \mathrm{q}}^{\mathrm{N}} \gamma L_{e f f} P T_{O D N}^{h}$

$\emptyset_{\mathrm{NLSPM}}=\gamma L_{e f f} P T_{O D N}^{p}$

where $p$ and $q$ represents number of $\mathrm{D} / \mathrm{L}$ and $\mathrm{U} / \mathrm{L}$ channels.

The range of non-linear phase change $\emptyset_{N L}$ is between 0.2 to 0.5 rad. Referring Eq. 10 and Eq.11 and incorporating $\mathrm{PT}_{\mathrm{ODN}}=7.1 \mathrm{dBm}$ for $\mathrm{D} / \mathrm{L}$ optical spectrum, the corresponding kerr parameter $\gamma$ for SPM and $\mathrm{XPM}$ is estimated as $7.98 \times 10^{-3} \mathrm{~W}^{-1} \mathrm{~m}^{-1}$ and $2.00 \times 10^{-2} \mathrm{~W}^{-1} \mathrm{~m}^{-1}$ respectively (Kumar et al. 2014; Neophytos et al. 2012; Zhou et al. 2015). Replacing the estimated kerr $\gamma$ parameter in Eq. 8, the effective area corresponding to SMP and XPM is estimated as $A_{\text {eff }}=123 \mu \mathrm{m}^{2}$ and $49 \mu \mathrm{m}^{2}$ and incorporated for simulative analysis of proposed network between 20 to $50 \mathrm{~km}$ link length to analyze the impact of launch power on BER, Q-fator, Rxs, network reach and link power budget.

\subsection{Estimation of Four-wave mixing (FWM) element}

Multichannel optical spectrum have significant impact of FWM. The FWM develops the addition signal element of specific magnitude located at specific frequency or wavelength. This results in overlapping of the channels also reducing the available bandwidth for the propagation of the original optical channels. The newly developed FWM elements are estimated using Eq. 12 as (Habib et al. 2020; Singh et al. 2018),

$\mathrm{N}_{\mathrm{f}}=\frac{\mathrm{N}^{2}}{2}(\mathrm{~N}-1)$

where $\mathrm{N}$ represents total channels travelling through SM fiber. The magnitude of the newly developed frequency components due to FWM phenomena is estimated using Eq. 13 as (Kumar et al. 2014),

$\mathrm{P}_{\mathrm{FWM}}=\gamma P_{a} P_{b} P_{c} * L_{e f f}^{2} * \eta_{a b c n} \mathrm{e}^{-\alpha L}$

From Eq. 13, it is confirmed that the magnitude of the FWM component is directly proportional to non-linear kerr parameter $\gamma$, effective length of the channel, respective channel magnitude and the efficiency of the FWM component. Considering the spacing between the adjacent channels of $100 \mathrm{GHz}$ and referring the GVD dispersion $\beta 2$ of $19.744 \mathrm{ps} / \mathrm{nm} * \mathrm{~km}$ as estimated in Section 4.1, the FWM efficiency $\eta_{a b c n}$ is estimated using Eq. 14 (Kumar et al. 2014) as, 
$\eta_{a b c n}=\frac{\alpha^{2}}{\left.\alpha^{2}+4 \beta_{2}^{2}(2 \pi \Delta f)^{4}\right)}$

The linear and nonlinear impairments described by Eq. 7 such as GVD parameter $\beta 2$, Kerr parameter $\gamma$ in the range of $7.98 \times 10^{-3} \mathrm{~W}^{-1} \mathrm{~m}^{-1}$ and $2.00 \times 10^{-2} \mathrm{~W}^{-1} \mathrm{~m}^{-1}$ respectively and estimated range of effective area Aeff of 123-49 um² and 61-24 $\mathrm{um}^{2}$ for symmetric channel spectrum along with SPM and XPM non-linear impairments respectively (Singh et al. 2018; Shrama et al. 2016; Pagare et al. 2021), resulted in FWM efficiency of $1.65 \times 10^{-52}$. The magnitude of the FWM component estimated using Eq. 13 is in the range of $1 \times 10^{-53}$ to $1 \times 10^{-52}$. Thus, we conclude that the ODN channel launch power optimizations process is successful in keeping Kerr parameter $\gamma$, FWM efficiency and FWM power level at much lower level minimizing impact of linear and nonlinear impairments on multichannel spectrum travelling through SMF ODN in either direction.

\subsection{Estimation and analysis of Interchange crosstalk (Cc) and power penalty (Pc)}

The non-linear Kerr parameter contributing SPM and XPM impairments along with CD and FWM phenomena results in crosstalk between the channels in multichannel scenario. The crosstalk $\mathrm{Cc}$ for $\mathrm{D} / \mathrm{L}$ and U/L spectrum is estimated using Eq. 15 and Eq. 16 respectively as (ITU-T G,989.2 2019),

$C_{C}=\Delta P_{O N U}+$ Uniformity ${ }_{\mathrm{WM}}+10 \log _{10}\left[2 * 10^{\frac{-I_{A}}{10}}(N-3) * 10^{\frac{-I_{N A}}{10}}\right]$

$C_{C}=\Delta P_{O N U}+d_{\text {max }}+10 \log _{10}\left[2 * 10^{\frac{-I_{A}}{10}}(N-3) * 10^{\frac{-I_{N A}}{10}}\right] \mathrm{dB}$

where $\mathrm{N}$ represents the number of channels propagating in up/down direction, $\Delta P_{O N U}$ represents the maximum channel transmitter power difference as estimated and referred from section 3.1 and 3.2 for symmetric channels respectively and dmax represents the maximum power difference between the placement of ONUs in U/L channels equal to $6.54 \mathrm{~dB}$. Referring unformity factor for WDM CEx device of $1.5 \mathrm{~dB}$. Isolation between the adjacenet and non-adjacent channels of $\mathrm{I}_{\mathrm{A}}=40 \mathrm{~dB}$ and $\mathrm{I}_{\mathrm{NA}}=55 \mathrm{~dB}$ are referred from mux filter (Corning Opti. 2016) to estimate the inter-channel crosstalk for D/L and U/L symmetric channels using Eq. 15 and Eq. 16 as,

$C_{C}=3+1.5+10 \log _{10}\left[2 * 10^{\frac{-40}{10}}(8-3) * 10^{\frac{-55}{10}}\right]=-31.97 \mathrm{~dB}$ for $\mathrm{D} / \mathrm{L}$ multi-channel spectrum

$C_{C}=0+6.54+10 \log _{10}\left[2 * 10^{\frac{-40}{10}}(8-3) * 10^{\frac{-55}{10}}\right]=-30.12 \mathrm{~dB}$ U/L multi-channel spectrum 
The crosstalk power penalty corresponds to estimated channel crosstalk for Q of 5 and 6 for symmetric channels respectively at $50 \mathrm{~km}$ with an extinction ratio (ER) of 15 along with aggregate impact channel nonlinearities as estimated above, is obtained using Eq. 17 as [9],

$P_{C}=-5 \log \left(1-\frac{10^{\frac{2 C_{C}}{10}}}{\mathrm{~N}-1} * \mathrm{Q}^{2} *\left(\frac{\mathrm{ER}+1}{\mathrm{ER}-1}\right)^{2}\right)=-5 \log \left(1-\frac{10^{\frac{2(-31.97)}{10}}}{8-1} * 5^{2} *\left(\frac{10+1}{10-1}\right)^{2}\right)=0.0 \mathrm{~dB}$

Thus, we confirm that the estimated crosstalk power penalty corresponds to estimated channel crosstalk

obtained for symmetric channels spectrum is well within the boundaries of prescribed by ITU-T G.989.2 standards.

\section{Simulative analysis of network performance parameters}

$\lambda 1-\lambda 4$ and $\lambda 5-\lambda 8$ channels are supporting XGS-PON PtM 2.5 and WDM PtP 10 Gbps D/S channels respectively. Similarly, $\lambda 9-\lambda 12$ and $\lambda 13-\lambda 16$ channels are operating with XGS-PON PtM 2.5 and WDM PtP 10 Gbps U/S channels respectively. D/L channels are propagated on L-band frequencies from $187.1 \mathrm{THz}-187.8 \mathrm{THz}$ while U/L channels are propagated on C-band frequencies from 195.1 $\mathrm{THz}-195.8 \mathrm{THz}$ with channel spacing of $100 \mathrm{GHz}$ between $20-50 \mathrm{~km}$ channel link distances. The multichannel $\mathrm{D} / \mathrm{L}$ and $\mathrm{U} / \mathrm{L}$ optical spectrum is optimized to $\mathrm{PT}_{\mathrm{ODN}}=7.1 \mathrm{dBm}$ and $4.1 \mathrm{dBm}$ before launching on SMF in ODN through WDM CEx. The D/L and U/L output spectrum post optimization along with total impact of CD, SPM and XPM at $50 \mathrm{~km}$ is depicted in Fig. 4 (a) - (b) respectively. It is observed that the channels are spaced apart nicely without any signs of overlapping. The maximum difference in the U/L channel power recorded is $d \max =6.54 \mathrm{~dB}$, while for $\mathrm{D} / \mathrm{L}$ channels, the uniformity factor considered is 1.5 $\mathrm{dB}$. The FWM component generated is in the range of -53 to $-52 \mathrm{~dB}$ constituting crosstalk of $-31.97 /-30.12$ $\mathrm{dB}$ for $\mathrm{D} / \mathrm{L}$ and $\mathrm{U} / \mathrm{L}$ spectrum respectively.
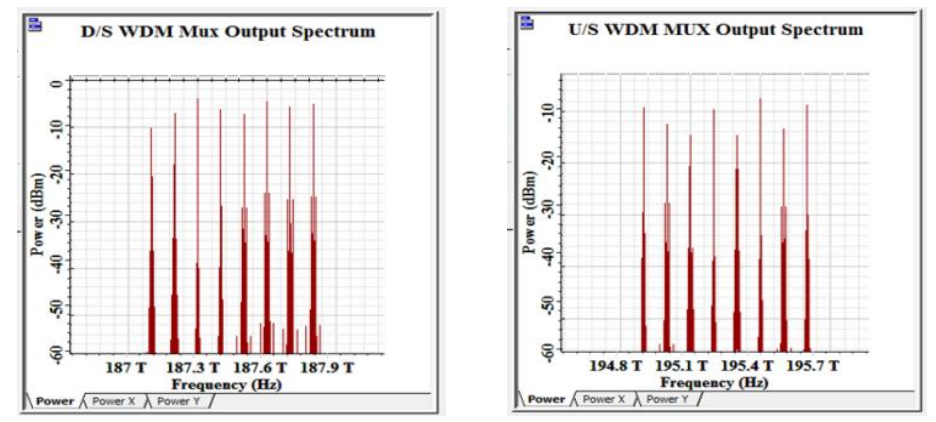

(a) Downstream channels Spectrum (b) Upstream channels Spectrum Fig. 4 (a) - (b) D/L and U/L spectrum for E1-class TWDM NG-PON2 network 
Fig. 5 (a) - (h). depicts the eye-diagram performance analysis of the optimized $\lambda 1$ - XGS-PON PtM 2.5 Gbps and $\lambda 8$-10 WDM PtP 10 Gbps D/L channels for optimized scenario of Kerr parameter $\gamma$, FWM and CD impairments between 20-50 km link distance. It is noted that the eye opening is good-enough up to $40 \mathrm{~km}$ link distance separating received 1's from 0's bits. The BER of -33 and -8 and Q of 11 and $511 \lambda 1-$ XGSPON PtM 2.5 Gbps and $\lambda 8$-WDM PtP $10 \mathrm{Gbps}$ D/L at $50 \mathrm{~km}$ comfortably satisfying ITU-T G. 989.2 specifications.

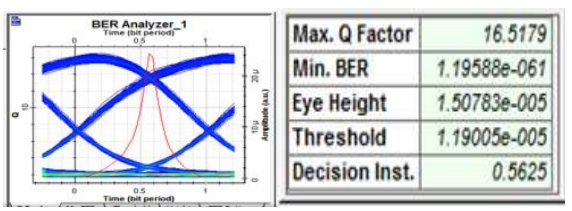

(a) $\lambda 1$ - XGS-PON PtM 2.5 Gbps D/L Ch. at $20 \mathrm{~km}$

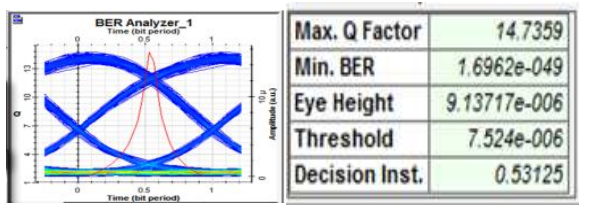

(c) ) $\lambda 1$ - XGS-PON PtM 2.5 Gbps D/L Ch. at $30 \mathrm{~km}$

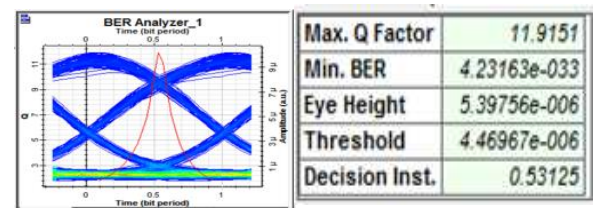

(e) $\lambda 1$ - XGS-PON PtM 2.5 Gbps D/L Ch. at $40 \mathrm{~km}$

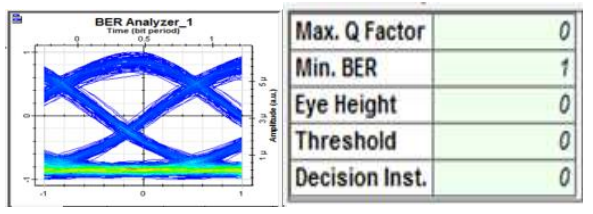

(g) $\lambda 1$ - XGS-PON PtM $2.5 \mathrm{Gbps}$ D/L Ch. at $50 \mathrm{~km}$

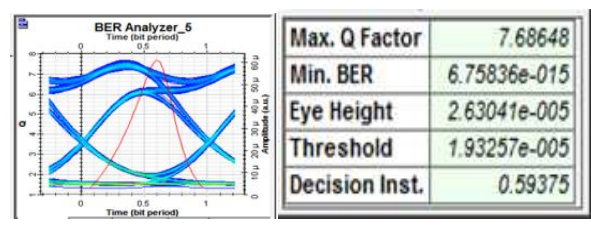

(b) $\lambda 8$-10 WDM PtP 10 Gbps Ch. at $20 \mathrm{~km}$

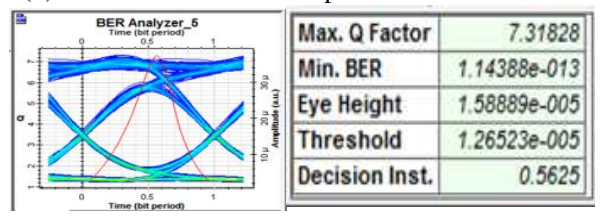

(d) $\lambda 8$-10 WDM PtP 10 Gbps Ch. at $30 \mathrm{~km}$

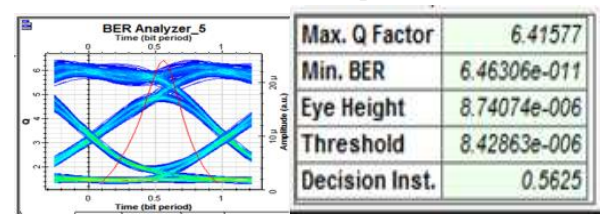

(f) $\lambda 8-10$ WDM PtP 10 Gbps Ch. 40 km

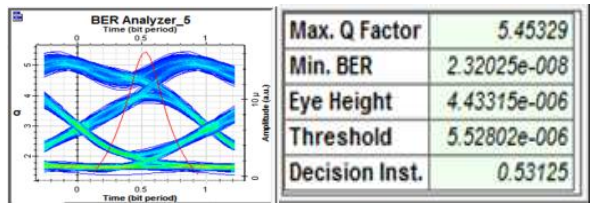

(h) $\lambda 8$-10 WDM PtP 10 Gbps Ch. 50 km

Fig. 5 (a) - (h). Eye diagram analysis of $\lambda 1$ - XGS-PON PtM 2.5 Gbps and $\lambda 8$-WDM PtP 10 Gbps D/L channels between 20$50 \mathrm{~km}$ link distance for optimized scenario of Kerr parameter $\gamma$, CD and FWM SMF channel impairments

The recorded magnitude of BER, Q-factor, received power and estimated receiver sensitivity (Rxs) for $\lambda 1$ XGS-PON PtM 2.5 Gbps and $\lambda 8$ WDM PtP $10 \mathrm{Gbps}$ D/L channels for optimized scenario of Kerr parameter $\gamma$, FWM and CD impairments between 20-50 km link distance are consolidated in Table 2. The observations has confirmed that $\lambda 1$ - XGS-PON PtM 2.5 Gbps D/L channels delivers the acceptable performance parameters up to $40 \mathrm{~km}$ link distance, while, $\lambda 8$-WDM PtP $10 \mathrm{Gbps}$ D/L channel delivers extended reach up to $50 \mathrm{~km}$. 
Table 2 Receiver sensitivity (Rxs), BER, Q-factor of $\lambda 1$ - XGS-PON PtM 2.5 Gbps and $\lambda 8$ - WDM PtP 10 Gbps D/S channels between 20-50 km link distance for optimized scenario of Kerr parameter $\gamma$, CD and FWM SMF channel impairments

\begin{tabular}{|c|c|c|c|c|c|c|c|c|c|c|c|}
\hline \multirow{2}{*}{$\begin{array}{l}\text { Sr. } \\
\text { No. }\end{array}$} & \multirow{2}{*}{$\begin{array}{c}\text { Link } \\
\text { Dista } \\
\text { nce } \\
(\mathbf{K m})\end{array}$} & \multicolumn{5}{|c|}{$\begin{array}{l}1-\text { XGS-PON PtM } 2.5 \text { Gbps } \\
\text { D/S Ch. }\end{array}$} & \multicolumn{5}{|c|}{$\begin{array}{c}\text { 28-WDM PtP } 10 \text { Gbps } \\
\text { D/S Ch. }\end{array}$} \\
\hline & & $\begin{array}{l}P \mathbf{P T}_{\lambda} \\
(\mathbf{d B m})\end{array}$ & $\begin{array}{c}\begin{array}{c}\text { Received } \\
\text { Power } \\
(\mathrm{dBm})\end{array} \\
\end{array}$ & $\begin{array}{c}\mathbf{R x s} \\
(\mathbf{d B m})\end{array}$ & $\begin{array}{c}\text { Q- } \\
\text { Fact } \\
\text { or } \\
\end{array}$ & BER & $\begin{array}{l}P T x \lambda \\
(\mathbf{d B m}) \\
\end{array}$ & $\begin{array}{c}\begin{array}{c}\text { Receive } \\
\text { d Power } \\
(\mathrm{dBm})\end{array} \\
\end{array}$ & $\begin{array}{c}\text { Rxs } \\
(\mathbf{d B m})\end{array}$ & $\begin{array}{c}\text { Q- } \\
\text { Fact } \\
\text { or }\end{array}$ & BER \\
\hline 1 & 20 & 6.55 & -23.33 & -33.97 & 16 & -61 & 9.55 & -15.72 & -27.36 & 8 & -15 \\
\hline 2 & 30 & 6.55 & -25.16 & -35.8 & 14 & -49 & 9.55 & -17.68 & -29.32 & 7 & -13 \\
\hline 3 & 40 & 6.55 & -27.14 & -37.78 & 12 & -33 & 9.55 & -19.8 & -31.44 & 6 & -11 \\
\hline 4 & 50 & 6.55 & -29.11 & -39.75 & 0 & -1 & 9.55 & -21.81 & -33.45 & 5 & -8 \\
\hline
\end{tabular}

Fig. 6 (a) - (h) depicts the eye diagram simulative analysis for results for $\lambda 9$-XGS-PON PtM 2.5 Gbps and $\lambda 16$-WDM PtP 10 Gbps U/S channels for optimized scenario of Kerr parameter $\gamma$, CD and FWM SMF channel impairments between link distance of $20-50 \mathrm{~km}$. Observations and recoding of parameters has confirmed that $\mathrm{U} / \mathrm{L}$ channels delivers acceptable BER and Q performance up to $50 \mathrm{~km}$ and suitable for implementation of symmetric channels for the foreseen E1-class TWDM NG-PON2 optical access network. Although, 2.5 Gbps XGS-PON PtM U/L channels are supported by $30 \mathrm{~dB}$ amplifier to archive the demonstrated simulation results, while $10 \mathrm{Gbps}$ WDM PtP U/L channels delivers the results without amplification of $\mathrm{U} / \mathrm{L}$ channels.

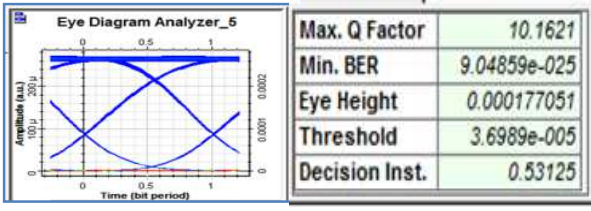

(a) $2.5 \mathrm{Gbps}-\lambda 9$-TWDM U/L Ch. at $20 \mathrm{~km}$

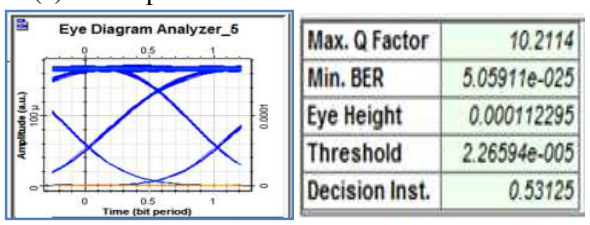

(c) 2.5 Gbps - $\lambda 9$-TWDM U/L Ch. at $30 \mathrm{~km}$

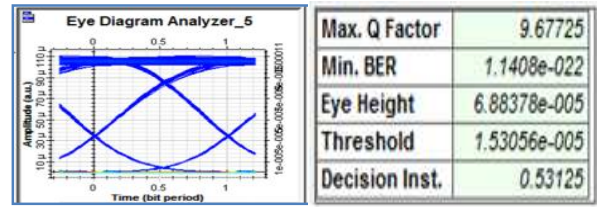

(e) 2.5 Gbps - $\lambda 9$-TWDM U/L Ch. at $40 \mathrm{~km}$

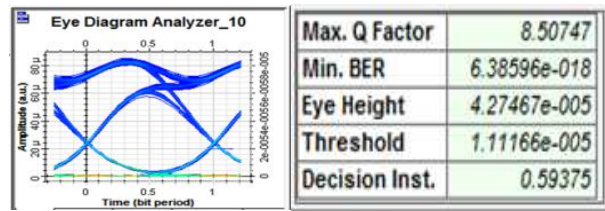

(b) 10 Gbps- $\lambda 16$ - PtP WDM U/L Ch. At $20 \mathrm{~km}$

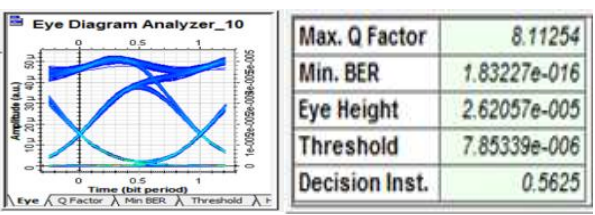

(d) 10 Gbps- $\lambda 16$ - PtP WDM U/L Ch. At $30 \mathrm{~km}$

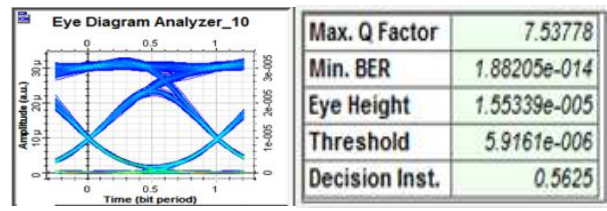

(f) 10 Gbps- $\lambda 16$ - PtP WDM U/L Ch. at $40 \mathrm{~km}$ 


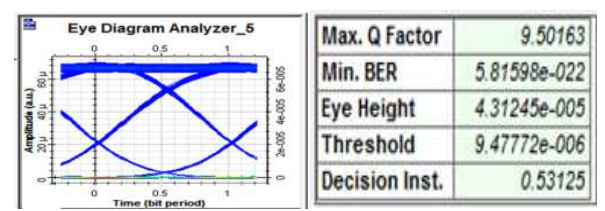

(g) $2.5 \mathrm{Gbps}-\lambda 9$-TWDM U/L Ch. at $50 \mathrm{~km}$

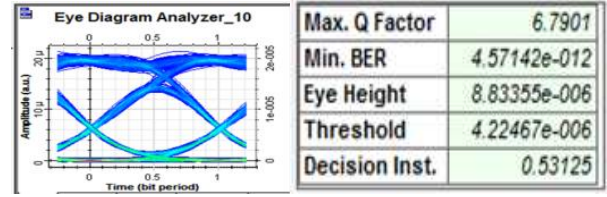

(h) 10 Gbps- $\lambda 16$ - PtP WDM U/L Ch.at $50 \mathrm{~km}$

Fig. 6 (a) - (h) Eye diagram analysis of $\lambda$ 9-XGS-PON PtM 2.5 Gbps and $\lambda 16-W D M$ PtP 10 Gbps U/S channels for optimized scenario of Kerr parameter $\gamma, \mathrm{CD}$ and FWM SMF channel impairments between 20-50 km link distance

Table 3 summarizes the BER, Q-factor, received power and estimated receiver sensitivity (Rxs) for $\lambda$ 9-2.5

Gbps PtM XGS-PON and $\lambda 16-10$ Gbps PtP WDM U/L channels for the optimized scenario of Kerr parameter

$\gamma$, FWM and CD impairments between 20-50 km link distance.

Table 3 Rxs, BER, Q-factor of $\lambda$ 9-XGS-PON PtM 2.5 Gbps and $\lambda 16$-WDM PtP 10 Gbps U/S channels for optimized scenario of Kerr parameter $\gamma, \mathrm{CD}$ and FWM SMF channel impairments between 20-50 km link distance

\begin{tabular}{|c|c|c|c|c|c|c|c|c|c|c|}
\hline \multirow{2}{*}{$\begin{array}{l}\text { Sr. } \\
\text { No. }\end{array}$} & \multirow{2}{*}{$\begin{array}{c}\text { Link } \\
\text { Distance } \\
(\mathbf{k m})\end{array}$} & \multirow{2}{*}{$\begin{array}{c}\text { Tx } \\
\text { Power } \\
(\mathbf{d B m})\end{array}$} & \multicolumn{4}{|c|}{$\begin{array}{c}\text { ג9-XGS-PON PtM } 2.5 \text { Gbps } \\
\text { U/S Ch. }\end{array}$} & \multicolumn{4}{|c|}{$\begin{array}{c}\lambda 16-W D M \text { PtP } 10 \text { Gbps U/S } \\
\text { Ch. }\end{array}$} \\
\hline & & & $\begin{array}{c}\text { Rx } \\
\text { Power }\end{array}$ & $\begin{array}{c}\text { Obtained } \\
\text { Sensitivity }\end{array}$ & $\begin{array}{c}\text { Q- } \\
\text { Factor }\end{array}$ & BER & $\begin{array}{c}\mathbf{R x} \\
\text { Power }\end{array}$ & $\begin{array}{c}\text { Obtained } \\
\text { Sensitivity } \\
\end{array}$ & $\begin{array}{c}\text { Q- } \\
\text { Factor }\end{array}$ & BER \\
\hline 1 & 20 & 5.55 & -10.02 & -22.46 & 10 & -25 & -15.09 & -29.33 & 8 & -18 \\
\hline 2 & 30 & 5.55 & -12.37 & -24.81 & 10 & -25 & -17.1 & -31.34 & 8 & -16 \\
\hline 3 & 40 & 5.55 & -14.19 & -26.63 & 9 & -22 & -19.01 & -33.25 & 7 & -14 \\
\hline 4 & 50 & 5.55 & -16.56 & -29 & 9 & -22 & -21.1 & -35.34 & 6 & -12 \\
\hline
\end{tabular}

It is confirmed that the optimization of channel power and impairments constituted an extended reach up to

$50 \mathrm{~km}$ is demonstrated for PtM and PtP U/L channels.

\subsection{Comparative performance analysis of $\lambda 1-\lambda 9-X G S-P O N$ PtM 2.5 Gbps $\lambda 8-\lambda 162.510$ Gbps symmetric channel pairs}

The comparative analysis of estimated receiver sensitivity Rxs, recorded BER and Q of $\lambda 1-\lambda 92.5$ Gbps

PtM and $\lambda 8-\lambda 1610$ Gbps PtP symmetric channel pair (CP) along the channel length between 20 to $70 \mathrm{~km}$

for lossless channel and under the optimized scenario of incremental channel impairments including Kerr parameter $\gamma$, CD and FWM is depicted in Fig. 7 (a) - (f). As depicted in Fig. 7 (a) and (b), the variations of Rxs is linear with link distance. The impact of channel impairments has limited the network reach to 40 and $50 \mathrm{~km}$ for $2.5 \mathrm{Gbps}$ and $10 \mathrm{Gbps}$ D/S CP respectively. Fig. 7 (c) and (d) depicts the variation of BER with Rxs. The impact of channel impairments are clearly observed on both the channels limiting the receiver sensitivity performance at acceptable BER. Similarly, the impact of channel imparities are also observed on Q-factor performance limiting the reach and Rxs of the channels. . 


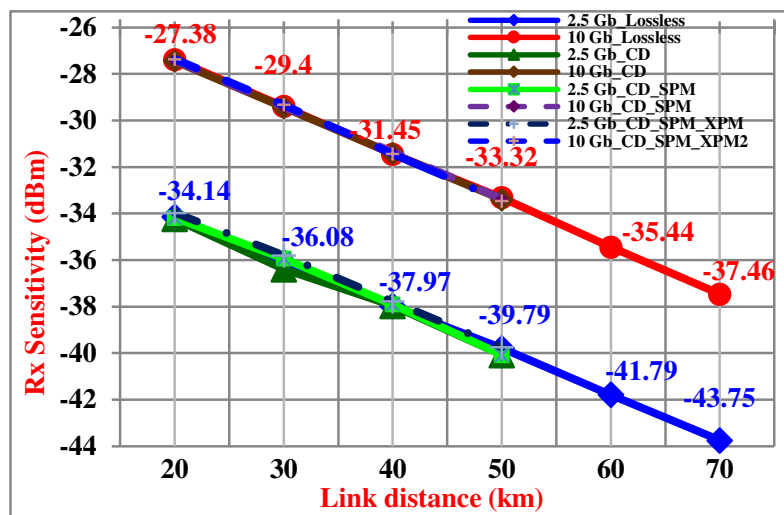

(a) Receiver sensitivity vs. link distance for $\lambda 1$-XGS-PON PON 2.5 and $\lambda 8$-WDM PtP $10 \mathrm{Gbps}$ D/S Ch.

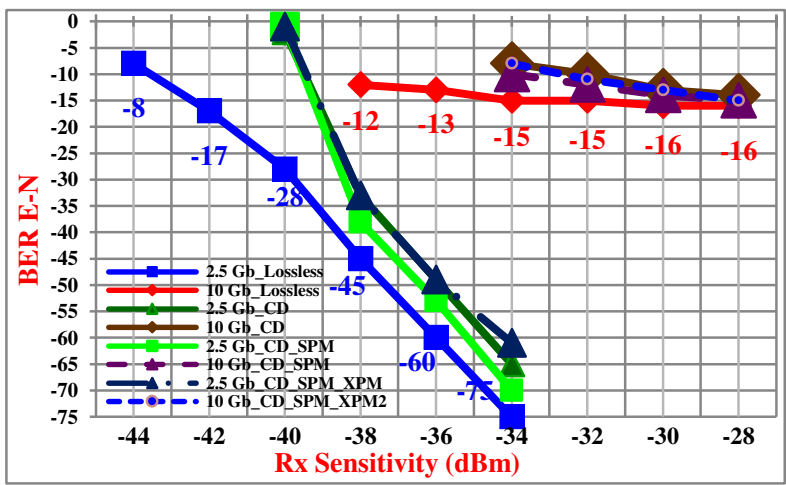

(c) BER vs Receiver sensitivity for $\lambda 1$-XGS-PON PtM 2.5 and $\lambda 8$-WDM PtP 10 Gbps D/S Ch.

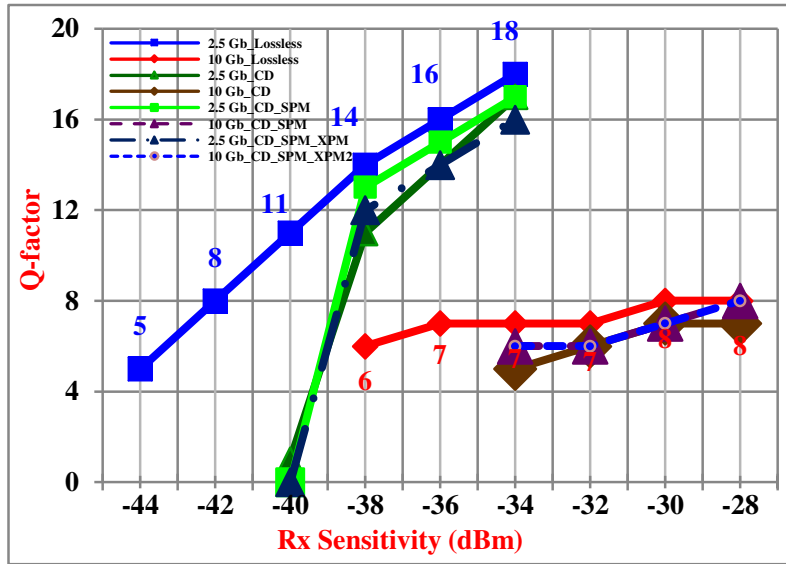

(e) Q-factor vs Receiver sensitivity for $\lambda 1$-XGS-PON PtM 2.5 and $\lambda 8$-WDM PtP 10 Gbps D/S Ch.

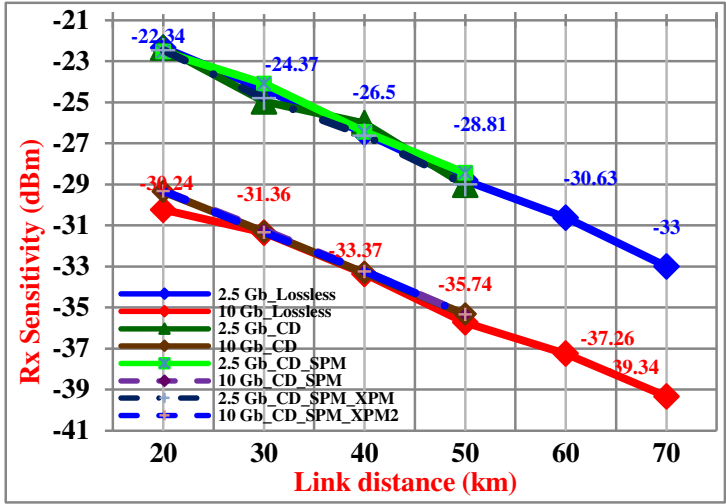

(b) Receiver sensitivity vs. link distance for $\lambda 9$-XGS2.5 and $\lambda 16-W D M$ PtP10 Gbps U/S Ch.

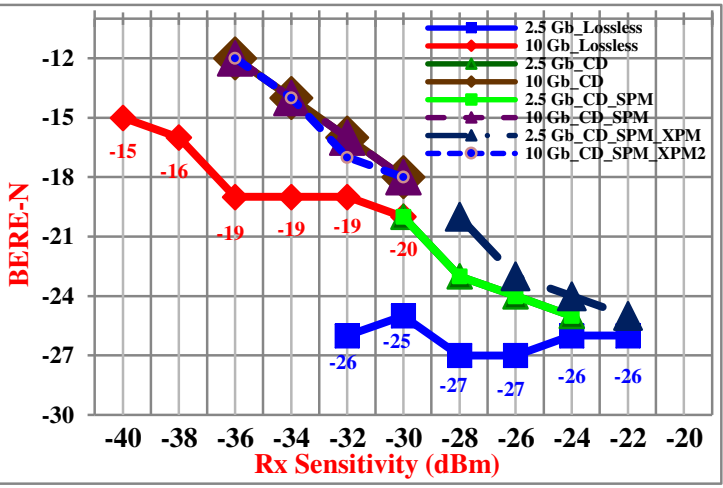

(d) BER vs Receiver sensitivity for $\lambda$ 9-XGS-PON PtM 2.5 and $\lambda 16-$ WDM PtP $10 \mathrm{Gbps}$ U/S Ch.

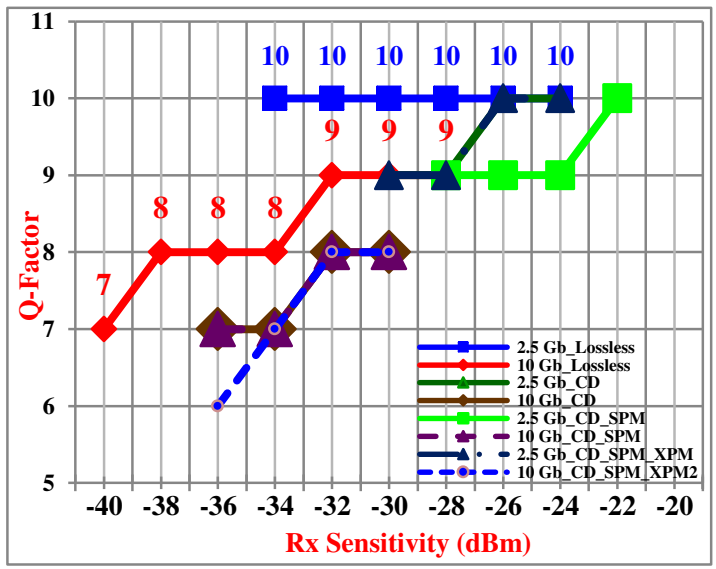

(f) Q-factor vs Receiver sensitivity for $\lambda 9-\mathrm{XGS}-\mathrm{PON}$ PtM 2.5 and $\lambda 16-W D M$ PtP 10 Gbps U/S Ch.

Fig. 7 (a) - (f) Comparative analysis of estimated receiver sensitivity Rxs, recorded BER and Q of $\lambda 1-\lambda 9$ 2.5 Gbps PtM and $\lambda 8-\lambda 1610$ Gbps PtP symmetric channel pair (CP) for lossless channel and under the optimized scenario of incremental channel impairments including Kerr parameter $\gamma, \mathrm{CD}$ and FWM along the channel length between 20 to $70 \mathrm{~km}$ 
The BER, Q and Rxs parameters obtained clearly indicated incremental performance compared to specifications described in G. 989.2 (02/2019). Upward trends in Rxs, will felicitate inclusion of splitter with higher split-ratio

\subsection{System power and splitter budget estimation}

System power budget $(\mathrm{PB})$ defines the minimum amount of optical power required to receive optical signal within acceptable performance parameters. Further, splitter power budget (SB) is derived from PB to confirm the splitter ratio supported by the downstream channels. System or link PB is estimated using Eq. 18 as, $\mathrm{PB}=$ Transmitter Power $\left(\mathrm{P}_{\mathrm{TX} \lambda}\right)-$ Receiver sensitivity $\left(\mathrm{R}_{\mathrm{XS}}\right)$

Referring estimated transmitter power $\mathrm{P}_{\mathrm{TX} \lambda}$ and estimated receiver sensitivity Rxs for $\lambda 1$ - XGS-PON PtM 2.5

Gbps and $\lambda 8$ WDM PtP 10 Gbps D/L channels at $40 \mathrm{~km}$ from Table 2, the PB of D/L channels is estimated as,

$\mathrm{PB}_{\lambda 1-\mathrm{XGS}-\mathrm{PON} \text { PtM } 2.5 \text { Gbps_D/S }}=6.55-(-39.75)=46.3 \mathrm{~dB}$

$\mathrm{PB}_{\lambda 8 \text { WDM PtP } 10 \text { Gbps_D/L }}=9.55-(-33.45)=43 \mathrm{~dB}$

PB for $\lambda$ 9- XGS-PON PtM 2.5 Gbps and $\lambda 16$ WDM PtP $10 \mathrm{Gbps}$ U/L channels is estimated by referring estimated $\mathrm{P}_{\mathrm{TX} \lambda}$ and Rxs for $\lambda 9$ and $\lambda 16 \mathrm{U} / \mathrm{L}$ channels at $50 \mathrm{~km}$ from Table 3 as,

$\mathrm{PB}_{\lambda 9-\mathrm{XGS}-\mathrm{PON} \text { PtM } 2.5 \mathrm{Gbps}_{-} \mathrm{U} / \mathrm{S}}=5.55-(-29)=34.55 \mathrm{~dB}$

$\mathrm{PB}_{\lambda 16-W D M}$ PtP 10 Gbps_U/L $=5.55-(-35.34)=40.89 \mathrm{~dB}$

Since the splitter will be incorporated in D/L channels only, SP of D/L channels is estimated using Eq. 19 as, $\mathrm{SP}=\mathrm{PB}-\mathrm{A}-$ Link Margin

where A is aggregate attenuation due to passive components and the fiber channel length estimated using Eq. 20 as (ITU-T G.652 2019),

$\mathrm{A}=\alpha L+\alpha \mathrm{s} \times S+\alpha \mathrm{c} \times C$

where $L$ is the channel length in $\mathrm{km}, S$ represents the number of splices incorporated in the link and $C$ is number of passive connectors used in the optical link. Incorporating the losses due to passive components and attenuation due to channel length, total attenuation ' $\mathrm{A}$ ' for $\lambda 1-2.5$ Gbps PtM XGS-PON and $\lambda 8-10$ Gbps PtP WDM D/L channel i.e. estimated as follows. 
$\mathrm{A}=\mathrm{IL}\left[\left(\mathrm{IL}_{\mathrm{MZM}}+\mathrm{IL}_{\mathrm{MUX}}+\mathrm{IL}_{\mathrm{Cir}+}+0.2 \mathrm{x}(40)\right]=(5.04+2.6+1+8)=16.64 \mathrm{~dB}\right.$ for $\lambda 1-2.5 \mathrm{Gbps}$ PtM XGS-PON D/L channel.

$\mathrm{A}=\mathrm{IL}\left[\left(\mathrm{IL}_{\mathrm{MZM}}+\mathrm{IL}_{\mathrm{MUX}}+\mathrm{IL}_{\mathrm{Cir}+} 0.2 *(40)\right]=(5.04+2.6+2+10)=19.64 \mathrm{~dB}\right.$ for $\lambda 8 \mathrm{WDM}$ PtP $10 \mathrm{Gbps} \mathrm{D} / \mathrm{L}$ channel.

From estimated power budget PB and total link attenuation A, the splitter power budget of $\mathrm{D} / \mathrm{L}$ channels are estimated using Eq. 19 as,

$\mathrm{SB}_{\lambda 1-\text { XGS-PON PtM } 2.5 \text { Gbps_D/S }}=6.3-16.64-3=26.66 \mathrm{~dB}$

$\mathrm{SB}_{\lambda 8 \text { WDM PtP } 10 \text { Gbps_D/L }}=43-19.64-3=20.36 \mathrm{~dB}$

The insertion losses introduced by the specific splitter configuration is estimated using Eq. 21 as (Comp-Port Tech. 2015),

PIL $_{\text {Splitter }}=10 \times \log \left(\frac{1}{N}\right)$

where $\mathrm{N}$ represents splitter ratio.

Based on the splitter budget ( $\mathrm{SB}$ ) of respective $\mathrm{D} / \mathrm{S}$ channels estimated, splitter ratio configuration is selected and incorporated in $\mathrm{D} / \mathrm{L}$ channels to deliver the multigigabit line rate to multiple subscribers. Aggregate splitter configuration supported by eight $\mathrm{D} / \mathrm{L}$ channels is 2560 at $20 \mathrm{~km}$ and 768 at $0 \mathrm{~km}$ respectively for optimized scenario of Kerr parameter $\gamma$, CD and FWM SMF channel impairments ( ITU-T G. 9807.1 2016; IYU-T G. 984.5 2014; ITU-T G. Sup39 2016).

\subsection{Splitter Budget Vs Link Distance Analysis}

The variation of link power budget PB and corresponding splitter configuration along with the link distance for link distance $\lambda 1$ - XGS-PON PtM 2.5 Gbps and $\lambda 8$ WDM PtP $10 \mathrm{Gbps}$ D/S channels for optimized scenario of Kerr parameter $\gamma, \mathrm{CD}$ and FWM SMF channel impairments between 20-50 km is depicted in Fig. 8 (a) and (b) respectively. Since the $\mathrm{D} / \mathrm{L}$ launch power is optimized to $\mathrm{PT}_{\mathrm{ODN}}=7.1 \mathrm{dBm}$, the power budget variations is linear almost similar for the incremental impact of CD, SPM and XPM impairments. The PB estimation has recorded almost $4 \mathrm{~dB}$ variations along with network reach by $20 \mathrm{~km}$ under the scenario of lossy fiber channel constraints. The splitter ratio accommodated by the proposed E1-class TWDM NG-PON2 optical access network is in the range of 2560 to 768 between 20-40 km link lengths respectively (Pagare et al. 2021; ITU T G.9807.1 2016, Comm-Port Tech. 2015). 


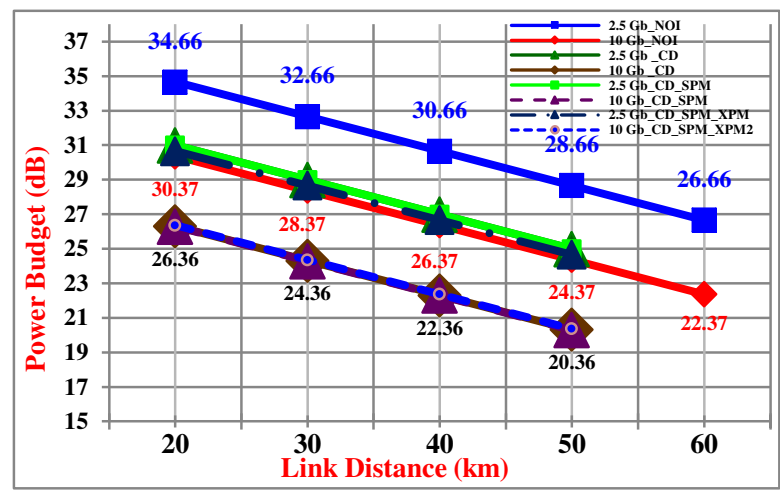

(a) Power budget vs Link distance of $\lambda 1$-XGS-PON PtM 2.5 and $\lambda 8$-WDM PtP 10 Gbps D/S Ch.

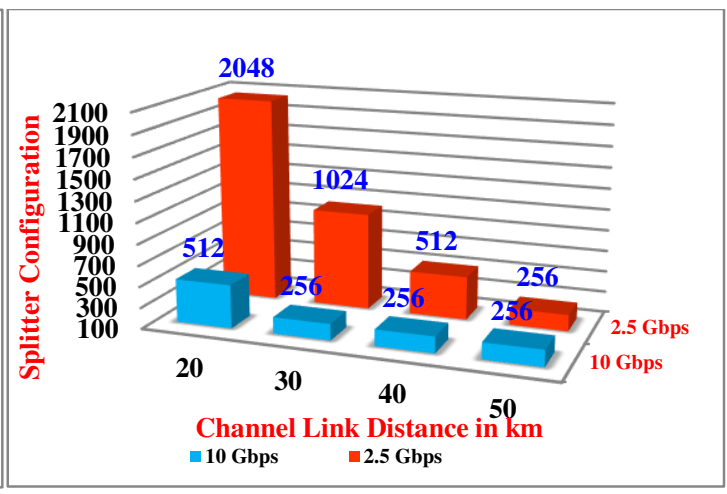

(b) Splitter ratio vs Link distance of $\lambda 1-\mathrm{XGS}-\mathrm{PON}$ PtM 2.5 and $\lambda 8$-WDM PtP 10 Gbps U/S Ch.

Fig. 8 (a)-(b) Variation of system power budget and aggregate splitter ratio of $\lambda 1-2.5$ Gbps PtM XGS-PON and $\lambda 8-10$ Gbps PtP WDM D/L channels between $20-60 \mathrm{~km}$ link distance for optimized Kerr parameter $\gamma$, FWM, and CD impairments

\section{Conclusion}

We have analyzed the impairment strained optical channel crosstalk subsequently affecting the link length due to dispersion, power budget limiting the channel splitter budget and splitter configuration incorporated in the system due to FWM, SPM and XPM. The optimization of ODN to N2-class by ensuring $\mathrm{PT}_{\mathrm{ODN}}=5$ $\mathrm{dBm}$ and $4 \mathrm{dBm}$ shown significant improvement in the network quality parameters like BER, Q-factor, receiver sensitivities, FWM component power and efficiency, inter-channel cross talk, power penalty and link power budget subsequently extending the link reach to $50 \mathrm{~km}$ and improving splitter budget and splitter configuration fulfilling ITU-T G.989.2 recommendations. Future investigations should be directed in incorporating spectrally efficient efficiency modulation schemes, reducing ODN power losses to accommodate growing subscribers, dispersion and FWM compensation techniques and management, incorporation of multistage switching network along with free space optics (FSO) channels to address last mile issues in the design and deployment of next generation optical access network for FTTX services. 


\section{References}

Ali, F., Khan, Y., Ali, A., Ahmed, G. : Minimization of nonlinear impairments and its impact on transmission performance of high-capaity long-haul optical networks. J. of optical Comm. (Ahead of print) (2018). http://doi.org/10.1515/joc-2018-0092

Ciena Corporation : Common optical filters for 4200 family, datasheet. Linthicum (2011). https://media.ciena.com/documents/Common_Optical_Filters_DS.pdf.

Cisco visual networking index forecast and trends: 2017-2022, Cisco white paper (online). 01-38, CISCO, California,(2019). http://media.mediapost.com/uploads/CiscoForecast.pdf.

Comm-Port Technologies : PLC splitter datasheet. Cranbu (2015). https://www.commport.com/images/fiber-optic/PLC\%20Splitter.pdf

Corning Optical Communications LLC : Optical circulators (Three Port), datasheet. Hickory (2016). www.corning.com/microsites/coc/oem/documents/CAH-140_AEN.pdf.

Goyal, R., Kaler, R.S., Rani, M., Singh, V.: Analysis and mitigation of XPM crosstalk in the scenario of mixed line rates for next generation access networks, J. Optoelectron. Adv. Mater. - Rapid Commun. 11 (7-8) 440-445 (2017). https://doi.org/10.1109/JLT.2015.2399271

Habib, U., Muhammad, Z., Sana, M., Talha, K., Songzuo J. et.al., : Improving FWM efficiency in bidirectional ultra DWDM-PON networking centered light source by using PMD emulator. Results in Physics, 16, 102922, (2020). http://doi.org/10:1016/rinp.2019.102922

ITU-T G.652 Series-G. ITU-T : Transmission media and optical systems characteristics-Optical fiber cable single mode optical fiber and cables, ITU-T, Geneva (2019). www.itu.int/rec/T-REC-G.652-201611-I/en

ITU-T G.984.5 Series-G. : Gigabit-capable passive optical network (GPON) Enhancement band. Geneva, (2014). www.itu.int/rec/dologin_pub.asp? lang=e\&id=T-REC-G.984.5-201405-I!!PDF-E\&type-items.

ITU-T G.989.2 Series-G. 40 Gbps capable passive optical networks 2 (NG-PON2) : Physical media dependent (PMD) layer specification, ITU-T, Geneva, (2019). www.itu.int/rec/T-REC-G.989.2-201902I/en.

ITU-T G.Sup39. : Optical system design and engineering considerations. Geneva, (2016). www.http://www.itu.int/rec/T-REC-G.Sup39/en.

ITU-TG.9807.1 (2016) Amendment-1 : 10-Gigabit-capable symmetric passive optical network (XGSPON), ITU-T, Geneva, 2017, www.itu-int/rec/T-REC-G. 9807.1/en.

IX-Blue Photonics : MX-LN series $1550 \mathrm{~nm}$ intensity modulators, datasheet. Besancon (2019) https://photonics.ixblue.com/sites/default/files/2021-02/MX-LN_SERIES_8.pdf

Jeff, S., Charls, M., Lauran, H. : Broadband applications: categories, requirments and future framework, J.Internet 17 (11) (2012). http://doi.org/10/5210/fm.v17i11.4066

Koundal, A., Dewra, S. : Performance analysis of $4 \times 10$ Gbps OFDM-PON system over ROF link, J. Opt. Commun. 40 (2), 113-117 (2019). https://doi.org/ 10.1515/joc-2017-0049.

Kumar S., Jamal M.D. : Fiber optics communications: Fundamentals and Applications. John Wiley \& Sons Ltd., New York (2014). 
Neophytos, A., Georgios, E., Ioannis, R. : WDM Systems and Networks, Springer, New York (2012).

Pagare, R.A., Kumar, S., Mishra, A. : Design and analysis of hybrid optical distribution network for worstcase scenario of E2-class symmetric coexistence $80 \mathrm{Gbps}$ TWDM NG-PON2 architecture for FTTX access networks, Optik J. Light Electron Optics, 228166168 (2021), https://doi.org/10.1016/j.ijleo.2020.166168.

Sharma, R., Dewra, S., Rani, A. : Performance analysis of hybrid PON (WDM-TDM) with equal and unequal channel spacing. J. Opt. Commun. 37 (2), 247-252 (2016). https://doi.org/10.1515/joc-2015-0055.

Singh, A., Singh J.S. : A noval method for capacity enhancement of fiber and minimization of four wave mixing in WDM optical network. Pro. of Computer Science, 125, 257-266 (2018). http://doi.org/10.1016/j.procs.2017.12.035

Veen, D.T.V., Houtsma, A., Gnauck, Iannoe, P. : Demonstration of 40 Gbps TDM-PON over 42- km with $31 \mathrm{~dB}$ optical power budget using an APD-based receiver J. Lightwave Technology, 33 (8), 1675 (2015). http://doi.org/10.1109/JLT.2015.2399271

Wey, J.S., Derek, N., Valvo, M., Grobe, K., Roberts, H., Luo, Y., Smith, J. : Physical layer aspect of NGPON2 standards-Part 1: Optical link design. J. Opt. Commun. Netw. 8 (1), 33-42 (2016). https://doi.org/10.1364/JOCN.8.0000433.

Yuanqiu, L., Klaus, G., Hal, R., Maurizio, V., Derek, N., Kota, A., et.al. : Physical layer aspect of NGPON2 standards-Part 2:System design and technology feasibility. J. optical communication and networking 8 (1), 43-52 (2016). http://doi.org/10.1364/JOCN.8.000043

Zhou, Z., Bi, M., Xiao, S., Zhang, Y. and Hu, W. : Exprimental demonstration of symmetric 40 Gbps DML based TWDM-PON system, Photonic Techno. Lett., 27(5), 470-473 (2015). http://doi.org/10.1109/LPT.2014.2377271

\section{Authors and Affiliations}

\section{Rajendraprasad A. Pagare, ${ }^{* 1}$ Abhilasha Mishra, ${ }^{2}$ Santosh Kumar ${ }^{3}$}

$1 \quad$ Savitribai Phule Pune University, Department of E\&TC Engineering

Smt. Kashibai Navale College of Engineering, Pune, Maharashtra, India,411042

2 Dr. BAM University, Department of E\&TC Engineering, Maharashtra Institute of Technology, Aurangabad, Maharashtra, India,431009

3 Liaocheng University, Shandong Key Laboratory of Optical Communication Sci ence and Technology, School of Physics Science and Information Technology, Liaocheng, Shandong, China, 252059 